\title{
A profile of Perthes' disease in Greater Glasgow
}

\author{
IS THERE AN ASSOCIATION WITH DEPRIVATION?
}

S. Sharma, M. Sibinski, D. A. Sherlock

From the Royal Hospital for Sick Children, Glasgow, Scotland
S. Sharma, FRCS(G), FRCS(Ed), Specialist

Registrar in Orthopaedics M. Sibinski, MD, PhD, Clinical Fellow in Orthopaedics

D. A. Sherlock, DPhil, FRCS, Consultant Orthopaedic Surgeon Royal Hospital for Sick Children, Dalnair Street, Glasgow G3 8SJ, UK.

Correspondence should be sent to Mr S. Sharma at 47 Shuna Place, Newton

Mearns, Glasgow G77 6TN, UK; e-mail:

sssharma2@yahoo.co.uk

(C)2005 British Editorial Society of Bone and Joint Surgery

doi:10.1302/0301-620X.87B11. $16608 \$ 2.00$

$J$ Bone Joint Surg [Br] 2005;87-B:1536-40.

Received 13 April 2005; Accepted 10 May 2005

It has been reported that there is an association between Perthes' disease and poverty. We examined the demographic data of a group of 240 children (263 hips) who presented with Perthes' disease in Greater Glasgow, where the mean deprivation scores are substantially greater than in the rest of Scotland, to see if this association applied and whether other clues to the aetiology of Perthes' disease could be found. There were 197 boys and 43 girls; $39(16.25 \%)$ had a family history of Perthes' disease. Bone age in this series was heavily skewed towards the lower percentiles. The mean number of siblings was 1.9 , with $31(12.9 \%)$ being an only child. Maternal age at the birth of the first child showed no preponderance of older mothers. Maternal smoking during and after pregnancy was noted in $132(55 \%)$, which compared with the $52 \%$ reported in the population of Greater Glasgow in general. Of the children in our series, $60(25 \%)$ were in social class IV and V. However, this applies to more than half of the population of Greater Glasgow. There was no significant evidence of a preponderance of Perthes' disease in the most deprived groups. The aetiology of Perthes' disease is likely to be multifactorial and may include a genetic or deprivation influence resulting in delayed bone age.

The pathology of Perthes' disease is believed to be a form of avascular necrosis of the capital epiphysis, but we do not know why certain children develop the condition. The incidence of Perthes' disease varies widely. It is common in Caucasians and rare in coloured children. ${ }^{1-3}$ Various authors have examined the demographic differences between children who develop Perthes' disease and those who do not. Factors such as minor congenital abnormalities and skeletal anomalies such as delayed bone age and disproportion between tibial and femoral growth have been described. ${ }^{4-16}$ Genetic factors have also been examined, ${ }^{17-22}$ but no significant genetic component has been found. Deprivation has also been implicated, but the only report to date ${ }^{23}$ to refute this view comes from an area with a very low incidence of Perthes' disease.

We have examined the demographic data for a group of children presenting with Perthes' disease in Greater Glasgow, where the mean deprivation scores are substantially greater than in the rest of Scotland. ${ }^{24-27}$ We have compared our results with those of other reports to determine if any further clues to the aetiology of Perthes' disease can be found.

\section{Patients and Methods}

The Royal Hospital for Sick Children serves children in the Greater Glasgow area. Between 1988 and 2004 data for every child presenting with Perthes' disease to the senior author (DAS) were collected. In each case, the diagnosis had been made on the basis of the clinical history, examination and recognised radiological changes. We analysed the data for annual incidence, age of onset, gender, laterality, family history and parental occupation. We noted the severity and phase of the disease at presentation. Other factors examined were associated diseases, birth weight, the number of siblings, bone age, height and weight at presentation and the maternal age and smoking status when the first child was born. We excluded patients with skeletal dysplasia and those outside the Glasgow post codes.

We examined the relationship between Perthes' disease and poverty by comparing the occupation of affected patients' parents with the general population of Greater Glasgow.

The patients were also graded according to their deprivation category (Depcat) $)^{24,27}$ which ranges from Depcat 1, which is the most affluent post-code sector to Depcat 7, which is the most deprived area. We compared the Depcat 


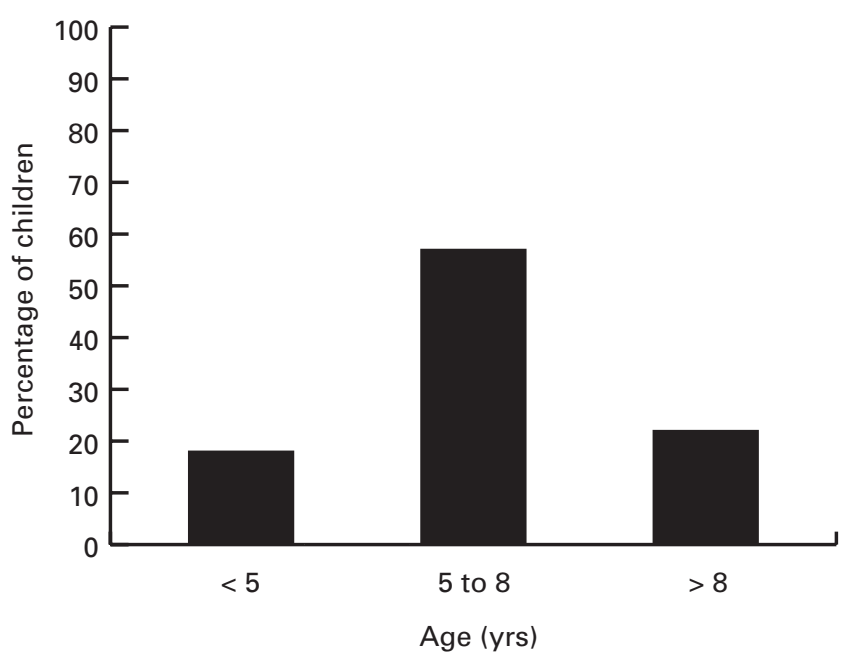

Fig. 1

Details of the age at diagnosis of the 240 patients.

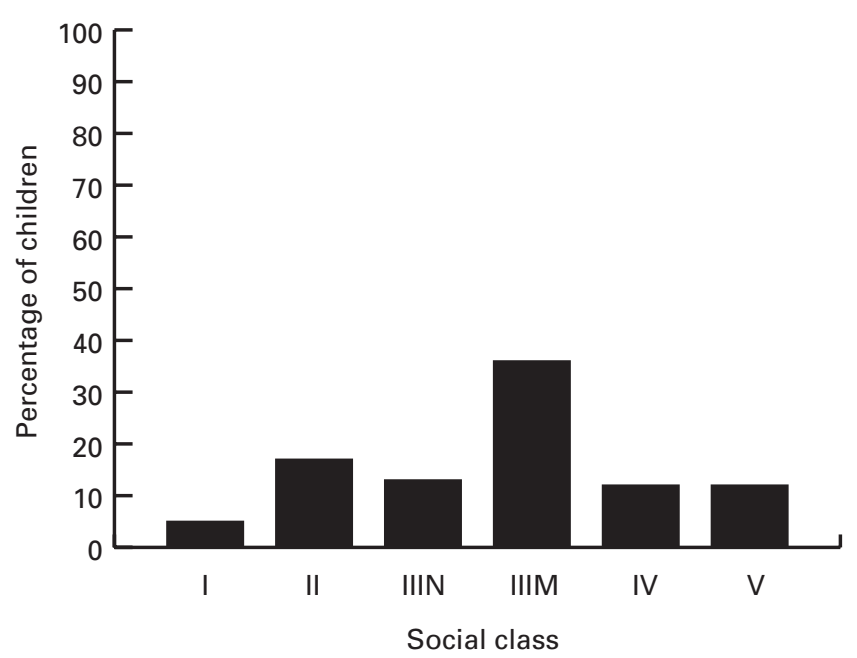

Fig. 3

Stratification of the families of the children according to social class by parental occupation (class I, professional occupation; class II, managerial and technical occupations; class IIIN, skilled occupations - non-manual; class IIIM, skilled occupations - manual; class IV, semi-skilled occupations; class V, unskilled occupations and unemployed).

scores of our patients with those of the population of Greater Glasgow Health board.

Statistical analysis. The Wilcoxon signed-rank test was used to assess numerical data and $\mathrm{p}$ values $<0.05$ were considered to be significant.

\section{Results}

Information was available for 250 patients but complete data only for 240 (263 hips). There were 197 boys and 43 girls. There were 105 right-sided, 112 left-sided and 23 bilateral cases. The age at diagnosis is shown in Figure 1.

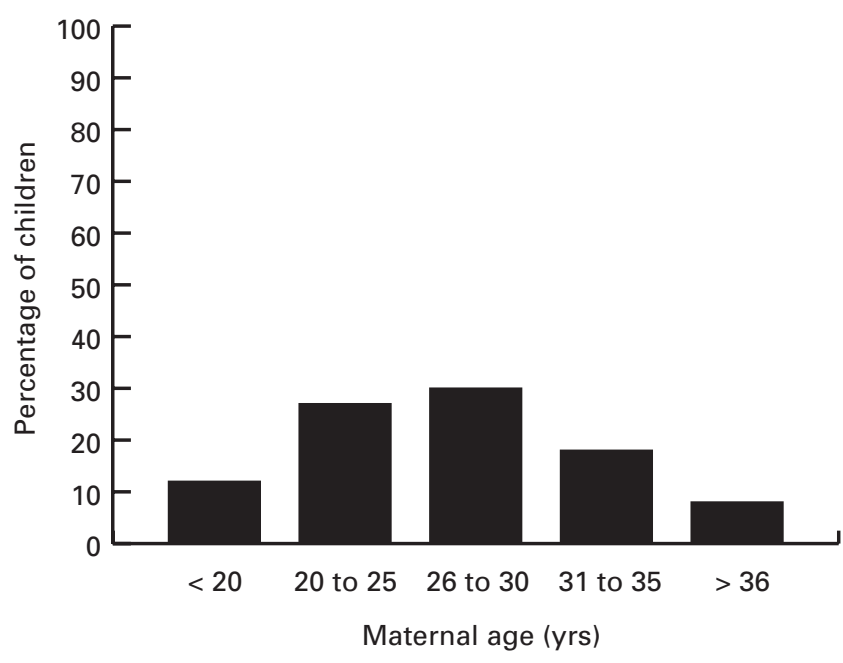

Fig. 2

Maternal age at birth of the first child.

Table I. Details of associated anomalies

\begin{tabular}{ll}
\hline Associated anomalies & Number of patients \\
\hline Developmental dysplasia of the hip & 2 \\
Congenital heart disease & 1 \\
Bowel malrotation & 1 \\
Multiple epiphyseal dysplasia & 2 \\
Hirschsprung's disease & 2 \\
VACTERL* syndrome & 1 \\
Hemiatrophy & 1 \\
Absent two lateral toes + short leg & 1 \\
Horseshoe kidney & 1 \\
Congenital hypothyroidism & 1 \\
Growth hormone deficiency & 1
\end{tabular}

* VACTERL, vertebral anomalies analatresia, cardiac malformations, tracheo-oesophageal fistula, renal anomalies and limb anomalies (humeral hypoplasia and radial aplasia)

The mean number of patients with Perthes' disease presenting each year was 15.1 (11 to 23$)$. There was a family history in $39(16.25 \%)$ of the children with Perthes' disease, in $24(10 \%)$ in first-degree relatives and in $15(6.25 \%)$ in second-degree relatives.

Most presented in the sclerosis phase with much smaller numbers in the other phases. The severity of the disease was graded using the Catterall classification; ${ }^{28} 184$ hips (70\%) were in Catterall grades 3 or 4 which tend to be associated with a poorer outcome.

The mean number of siblings was 1.9 (1 to 5), with 31 $(12.9 \%)$ patients being an only child. There was no evidence that the children with Perthes' disease were the least well-developed of the children in the family.

Maternal age at the birth of the first child is shown in Figure 2. There was no preponderance of older mothers. Maternal smoking during and after pregnancy was noted in $132(55 \%)$, which compared with $52 \%$ reported in the general population. ${ }^{29}$ 


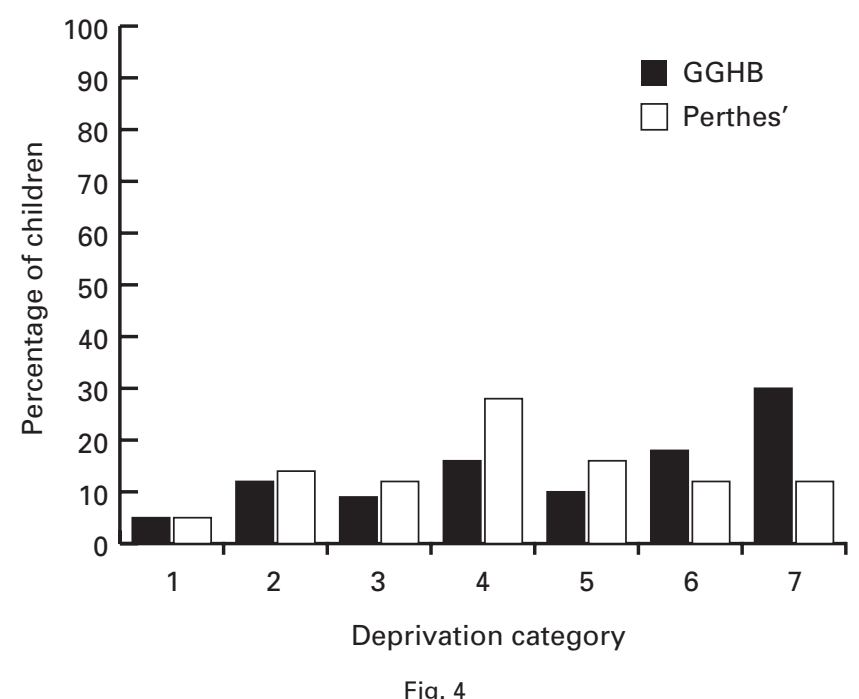

Comparison of the deprivation category (Depcat) scores of our patients with those of the population of Greater Glasgow Health Board (GGHB) in general.

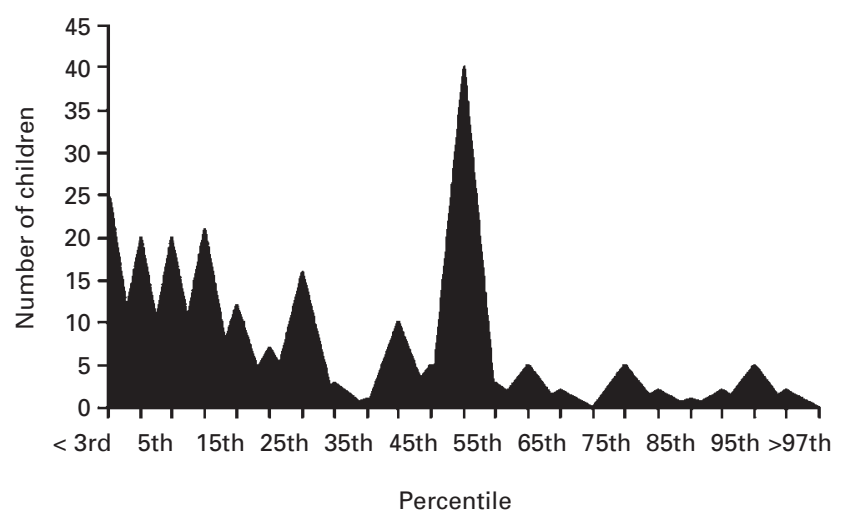

Fig. 5

The distribution of bone age by percentile.

The incidence of associated congenital anomalies or other conditions was low, at $5.8 \%$ (14 of 240) (Table I).

Figure 3 shows the distribution of children according to social class based on parental occupation. ${ }^{27}$ Only 60 (25\%) children in our series were in social class IV and $\mathrm{V}$, although this accounts for more than half of the population of the Greater Glasgow Health Board. ${ }^{27}$

The Depcat scores for the Greater Glasgow Health Board compared with those for our patients with Perthes' disease are shown in Figure 4. There was no significant evidence of a preponderance of Perthes' disease in the most deprived groups.

Bone age in our series was heavily skewed towards the lower percentiles (Fig. 5). The height, weight and birth weight of the patients with Perthes' disease are shown in

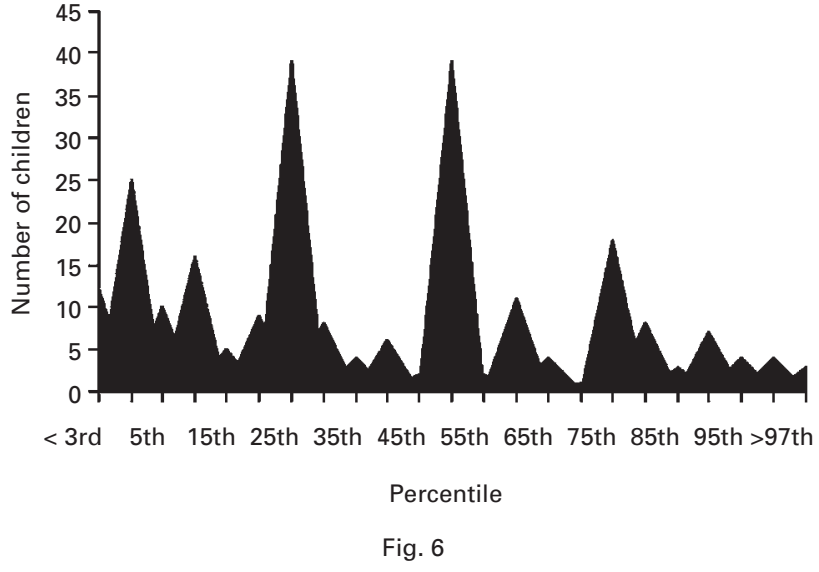

The distribution of height by percentile.

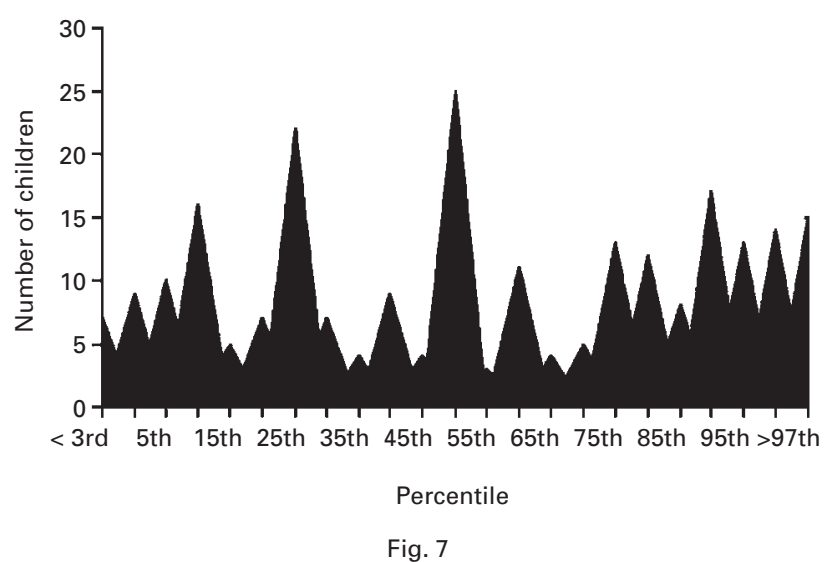

The distribution of weight by percentile.

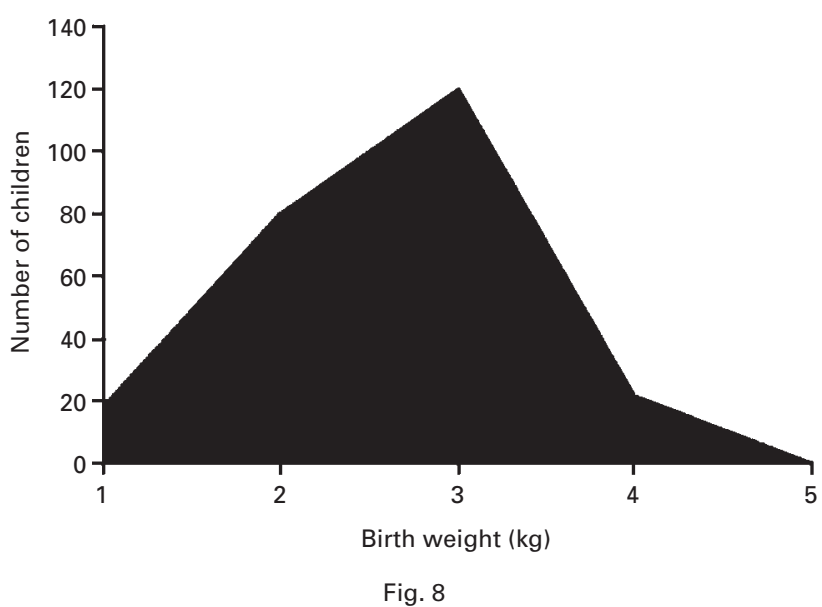

The distribution by birth weight.

Figures 6 to 8 . Birth weight showed a definite shift to the left, height a weaker shift to the left while weight followed a normal distribution. 


\section{Discussion}

Our series showed that the patients with Perthes' disease tended to have a low birth weight, which is similar to the findings of Lappin et al. ${ }^{30}$ Our patients also had reduced bone age, slightly reduced height, but normal weight at the time of diagnosis. In contrast to previous studies ${ }^{31,32}$ we have not shown an increased incidence in children from poor families in a large series from an area with a moderate incidence of Perthes' disease.

Our findings confirm those of Harper et $\mathrm{al}^{20}$ who showed no strong genetic basis for Perthes' disease although a family history of $16.25 \%$ in our series was higher than would be expected if there was no genetic effect at all. A multifactorial basis appears to be likely and could be one explanation for the wide variation in incidence seen around the world. In common with most series the majority of our patients were male, and presented between the ages of four and seven years. ${ }^{1-3,7-11}$ Unlike Burwell ${ }^{4}$ we did not find any clear association between minor congenital abnormalities or other diseases and Perthes' disease.

Previous studies ${ }^{31,32}$ of socio-economic variables have shown that the disease is related to indicators of material deprivation. Hall et al ${ }^{31}$ showed that children in Liverpool with Perthes' disease had a low level of manganese in the blood and suggested a possible dietary link. It has been postulated that poverty, possibly acting through malnutrition, may explain the delayed bone age and diminished height of children with Perthes' disease. However, in our series this would seem to be excluded by the identical profile of parental occupations between the patients with Perthes' disease and the general population. Also the affected children were of average weight which would not suggest malnutrition.

In the United Kingdom there is a strong social-class bias in the prevalence of smoking, which is more than twice as common among unskilled manual workers than in professional socio-economic groups. ${ }^{33}$ Socio-economic status therefore can be related to maternal smoking. ${ }^{34}$

However, older maternal age, smoking and the 'disadvantaged sibling' do not seem to apply to our cohort. The risk of passive smoking in the context of Perthes' disease is obscure. In the absence of any clear data on the exposure to passive smoking, any link to Perthes' disease is speculative.

Our findings suggest that some factors other than poverty may be involved. It seems quite clear that the aetiology of Perthes' disease is multifactorial. We believe that at least three separate components act together, although probably in varying degrees. The first is possibly a genetic influence, but poverty may have the same effect. This factor manifests itself as a delayed bone age. In the presence of a normal weight profile, this will expose the femoral head to greater loads. However, on its own this is not enough, since many children with delayed bone age and normal body-weight do not develop Perthes' disease.

A second factor is that many children with Perthes' disease seem to be hyperactive. We have not been able to quantify this but it is a constant theme reiterated by parents and observed in our clinics that many of these children are more active than average.

The third trend is that many of these children appear to have a high pain threshold. Again parents frequently say that the child is not one to cry after falling over. They just get up and carry on. 'Growing pains' or overuse pain are almost universal in children and are probably the method by which the skeleton protects itself from overuse. Various authors have suggested that repetitive trauma may be an aetiological factor in Perthes' disease. ${ }^{1-3,28}$ This could explain sequential or progressive infarction of the capital femoral epiphysis. In a child who has slightly weaker bones and is extremely active but does not know when to stop, these factors may combine to produce Perthes' disease.

No benefits in any form have been received or will be received from a commercial party related directly or indirectly to the subject of this article.

\section{References}

1. Purry NA. The incidence of Perthes disease in three population groups in the Eastern Cape region of South Africa. J Bone Joint Surg [Br] 1982;64-B:286-8.

2. Ebong WW. Legg-Calvé-Perthes disease in Nigerians. Int Surg 1977;62:217-18.

3. Coyle WJ. Perthes disease in Hong Kong. J West Pacific Orthop Assoc 1975;12:1-14

4. Burwell RG. Perthes' disease: growth and aetiology. Arch Dis Child 1988;63 1408-12.

5. Glueck CJ, Freiberg RA, Crawford A, et al. Secondhand smoke, hypofibrinolysis and Legg-Perthes disease. Clin Orthop 1998;352:159-67.

6. Glueck CJ, Friberg R, Tracy T, Stroop D, Wang P. Thrombophilia and hypofibrinoIysis: pathophysiologies of osteonecrosis. Clin Orthop 1997;334:43-56.

7. Kristmundsdottir F, Burwell RG, Harrison MHM. Delayed skeletal maturation in Perthes' disease. Acta Orthop Scand 1987;58:277-9.

8. Burwell RG, Dangerfield PH, Hall DJ, Vernon CL, Harrison MH. Perthes' disease: an anthropometric study revealing impaired and disproportionate growth. J Bone Joint Surg [Br] 1978;60-B:461-77.

9. Hall J, Barker DJP, Dangerfield PH, Osmond C, Taylor JF. Small feet and Perthes' disease: a survey in Liverpool. J Bone Joint Surg [Br] 1988;70-B:611-13.

10. Burwell RG, Vernon CL, Dangerfield PH, Hall DJ, Kristmundsdottir F. Raised somatomedin activity in the serum of young boys with Perthes' disease revealed by bioassay: a disease of growth transition? Clin Orthop 1986;209:129-38.

11. Raynor PAW, Schwalbe SL, Hall DJ. An assessment of endocrine function in boys with Perthes' disease. Clin Orthop 1986;209:124-8.

12. Tanaka H, Tamura K, Takano K, et al. Serum somatomedin A in Perthes' disease. Acta Orthop Scand 1984;55:135-40.

13. Hall DJ, Harrison MHM, Burwell RG. Congenital abnormalities and Perthes' disease: clinical evidence that children with Perthes' disease may have a major congenital defect. J Bone Joint Surg [Br] 1979;61-B:18-25.

14. Barker DJP, Hall AJ. The epidemiology of Perthes' disease. Clin Orthop 1986;209: $89-94$

15. Catterall A, Lloyd Roberts GC, Wynne-Davies R. Association of Perthes' disease with congenital anomalies of genito-urinary tract and inguinal region. Lancet 1971;1: 996-9.

16. Fisher RL. An epidemiological study of Legg-Perthes' disease. J Bone Joint Surg [Am] 1972;54-A:769-78.

17. Hall AJ, Margetts BM, Barker DJP, et al. Low blood manganese levels in Liverpool children with Perthes' disease. Paediatr Perinat Epidemiol 1989;3:131-5.

18. Szepesi K, Posan E, Harsfalvi J, et al. The most severe forms of Perthes' disease associated with homozygous Factor V Leiden mutation. J Bone Joint Surg [Br] 2004; 86-B:426-9.

19. Wynne-Davies R, Gormley J. The aetiology of Perthes' disease: genetic, epidemiological and growth factors in 310 Edinburgh and Glasgow patients. J Bone Joint Surg [Br] 1978;60-B:6-14.

20. Harper PS, Brotherton J, Cochlin D. Genetic risks in Perthes' disease. Clin Gen 1976;10:178-82

21. Burch PRJ, Nevalos AB. Perthes' disease: a new genetic hypothesis. Med Hypotheses 1979;209:100-14

22. Hall DJ. Genetic aspects of Perthes' disease: a critical review. Clin Orthop 1986;209 100-14. 
23. Hall AJ, Barker DJP. Perthes' disease in Yorkshire. J Bone Joint Surg [Br] 1989; 71-B:229-33.

24. Carstairs V, Morris R. Deprivation and health in Scotland. Aberdeen: Aberdeen University Press, 1991:1-240.

25. Greater Glasgow Health Board. The Annual Report of the Director of Public Health, 1991/1992.

26. Kipen AM. The validity in Glasgow of using the school post code to assign a socioeconomic indicator score to stratify the 5 year old sample in the 1995/1996 Scottish Health Board dental epidemiological programme. Health Bulletin 1998;56:635-40.

27. www.msoc-mrc.gla.ac.uk/Publications/pub/PDFs/Carstairs report (accessed 01/03/ 05).

28. Catterall A. The natural history of Perthes' disease. J Bone Joint Surg [Br] 1971; 53-B:37-53.
29. www.archive.official-documents.co.uk/document/Scottish/shealth/shch4.htm (accessed 01/03/05).

30. Lappin K, Kealey D, Cosgrove A, Graham K. Does low birthweight predispose to Perthes' disease? J Pediatr Orthop B 2003;12:307-10.

31. Hall AJ, Barker DJP, Dangerfield PH, Taylor JF. Perthes disease of the hip in Liverpool. Br Med J 1986;287:1757-9.

32. Kealey WDC, Moore AJ, Cook S, Cosgrove AP. Deprivation, urbanization and Perthes' disease in Northern Ireland. J Bone Joint Surg [Br] 2000;82-B:167-71.

33. Bennett N, Jarvis L, Rowlands 0, et al. Living in Britain 1994 General Household Survey. Office of Population Census and Surveys. London: Her Majesty's Stationery Office, 1996.

34. Gazmararian JA, Adams MM, Pamuk ER. Associations between measures of socioeconomic status and maternal health behaviour. Am J Prev Med 1996;12:108-15. 